\section{What We Talk About When We Talk About Repositories}

\author{
Mike Furlough, \\ Guest Columnist \\ Correspondence concerning this \\ column should be addressed to Diane \\ Zabel, Schreyer Business Library, The \\ Pennsylvania State University, 309 \\ Paterno Library, University Park, PA \\ 16802; e-mail: dxz2@psu.edu. \\ Mike Furlough is Assistant Dean \\ for Scholarly Communications \\ and Co-Director, Office of Digital \\ Scholarly Publishing, The Pennsylvania \\ State University, University Park, \\ Pennsylvania.
}

In this column, Mike Furlough writes about repositories from a user services perspective. His engaging and accessible article provides a fascinating history of repository hype, a primer on technical tools, and thoughtful reflections on the future of institutional repositories. Mike Furlough joined The Pennsylvania State University Libraries in 2006 as the assistant dean for Scholarly Communications and co-director of the Office of Digital Scholarly Publishing. Furlough's graduate training is in American Literature, but he ran away to join the University of Virginia Library, where he developed and led a number of services to support digital scholarship. He currently serves as a member of the Association of College and Research Libraries' Scholarly Communications Committee and begins editing a column on that topic for CERL News in 2009.-Editor

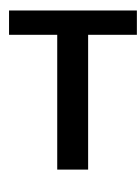

hroughout the past few years, I have come to dislike the word "repository" because it obscures the variety of problems we are attempting to address through their development, and in turn may constrain our thinking about what may be possible through the services they can enable. Modifiers such as "institutional," "central," "digital," "open," and "collections" (or some torturous combination of these) do not help because each variation implies a singular technological solution to a set of complex changes in the way research is conducted and information is communicated. "Repository" carries with it many connotations, some of them rather unfortunate. In general it describes a place where things lay, not where things are happening. According to the Oxford English Dictionary, a repository could be "a vessel, receptacle, chamber, etc., in which things are or may be placed, deposited, or stored" (definition 1.a). Definition 5- "A person to whom some matter is entrusted or confided"-is a less common use, but one that certainly resonates with the institutional mission and responsibilities that libraries hold for their collections. Yet it is also hard to overlook definition 2.b: "A place in which a dead body is deposited; a vault or sepulchre."1

"Institutional repository" (IR) often refers to a service that supports and encourages the deposit of student- and facultycreated materials, primarily open-access versions of research articles that have been formally published elsewhere or not at all. The early energy surrounding IRs centered on a hope that promoting open access could serve as a countermeasure to commercial publishing power and its ability to distort the market for knowledge. Taking control of our institutions' research by providing the ability to distribute this information to the world in an open-access mode seemed to be an 
inevitable outcome of the Internet. What follows is a brief history of IR hype.

In July 2002, The Chronicle of Higher Education reported "'Superarchives' Could Hold All Scholarly Output: Online Collections by Institutions May Challenge the Role of Journal Publishers." Also in 2002, a Scholarly Publishing and Academic Resources Coalition (SPARC) position paper declared that

institutional repositories-digital collections capturing and preserving the intellectual output of a single or multi-university community. . . . provide a critical component in reforming the system of scholarly communication - a component that expands access to research, reasserts control over scholarship by the academy, increases competition and reduces the monopoly power of journals, and brings economic relief and heightened relevance to the institutions and libraries that support them. ${ }^{3}$

But in 2004 The Chronicle provided an update: "Papers Wanted: Online Archives Run by Universities Struggle to Attract Material." "' IRs soon became the butt of jokes, even inside the community of practitioners. In March 2006, Dorothea Salo, an institutional repository manager, rechristened herself in her blog. "I have a new title. Innkeeper of the Roach Motel," she wrote, describing her repository as a site where data goes in but doesn't come out. ${ }^{5}$ By November 2008, attendees at the SPARC Repositories Conference worried openly about how faculty can be persuaded to use the IRs on their campuses and how these services were going to survive the worst economic crisis in decades if they didn't.

Many of my publishing colleagues have warned me that if IRs are successful they will go out of business, and eventually the entire scholarly communication system will start to break down. I can assure my friends that their jobs are quite safe. The emphasis on opening access has been driven heavily by our institutional (library) hopes, not the needs of our users, whose work is changing and who require new services to keep pace in their fields. Archiving single articles didn't make much sense to them in that context. While IRs have generally had limited success, many publishers have adapted their policies to allow authors to distribute pre- or postprint versions of articles in open-access forms. Those changes are at least partly related to funder and public pressure and the availability of repository outlets. Some institutions have begun to have luck negotiating with publishers for the rights to deposit their faculty's articles in those same repositories. However, continuing to focus on IR "deposits" by faculty and students-which sounds like a one-way proposition for the information-will not carry us forward.

Repository tools and many related programs have been developed with a potential scope of use broader than that implied by the IR hype, and may yet serve, as Clifford Lynch and Joan Lippincott wrote, as "general-purpose infrastructure within the context of changing scholarly practice." Deployment has varied. Some libraries have focused first on "the intellectual output of the institution," others have focused on particular disciplines or user groups, while still others have attempted to better manage and provide access to digitized versions of the physical collection of the library. Libraries also are using these services to manage born-digital resources acquired by the library from a variety of sources, including vendors and publishers. None of these activities are mutually exclusive, and it is likely that libraries will end up working with all of these materials simultaneously.

So what is it that we think we are talking about when we talk about repositories in research libraries today? Are repositories things? If so, they are more like conglomerate rocks than uniform applications and programs. Are they places, like the open stacks or the closed archives? If so, they are Victorian follies - an aggregation of features, not all of them fully functional, offering none of the transparency of Phillip Johnson's glass house. In the widest possible sense, when we are talking about repositories, we are talking about a set of organized methods for content management, not about specific applications or even specific access points online. Managing and providing access to diverse digital content requires many different processes, methods, policies, and technologies, just like a physical library collection. Collectively, we are today determining how to manage digital data as smoothly and with the same degree of certainty as we do physical collections. ${ }^{7}$ Repository-based content management can and must serve many functions at once, and successful implementations will recognize this to move beyond our early narrow focus to succeed. So, where do we begin? One potential answer to these questions is provided by Catherine Mitchell, who at the 2008 SPARC conference presented with the title "Let's Stop Talking About Repositories," arguing instead for a talk about services. ${ }^{8}$ That is a critically important, rhetorical shift.

\section{REPOSITORIES, TOOLS, AND THE LIFECYCLE OF DIGITAL INFORMATION}

Both DSpace and Fedora, two major open-source repository tools developed over the past decade, attempt to cover many of the needs for effective data management and access in a repository service. Though these are sometimes referred to as repositories in themselves, other platforms have been deployed that are based on commercial, community-based, and homegrown applications. Each of these has limitations and requires their own tradeoffs of convenience and functionality for users and for system managers.

DSpace, first released in 2001 through a development partnership between Hewlett Packard and MIT, has been promoted since its inception as an application meant to develop an institutional collection of research. The earliest instance of the dspace.org website found in the Wayback Machine, dated April 28, 2001, greets the reader: "Welcome to DSpace, a newly developed digital archive created to capture and distribute the intellectual output of MIT." DSpace provides a set of integrated tools, services, and functions designed to make repository start-up simple, which has led to broad adoption: over the last decade DSpace has been put into production at 


\section{FOR YOUR ENRICHMENT}

more than five hundred institutions around the world.

Fedora is an acronym for Flexible Extensible Digital Object Repository Architecture, which sums up the project's philosophy of enabling maximum flexibility and adaptability in the design, implementation, and use of its software. Fedora was initially conceived by researchers at Cornell University's Computer Science Department and later developed in partnership with the University of Virginia Library and with funding from the Andrew W. Mellon Foundation. From the start, Fedora has been marketed as the foundation for a wider variety of digital collection management needs, not as an integrated IR solution.

Both DSpace and Fedora recognize the needs of diverse disciplines and researchers. DSpace's interfaces define collections relevant to communities with different needs and expectations for distributing digital content online. Administrators have the ability to enable variable controls on input and access and support different formats, genres, and metadata structures to describe and document those materials. Fedora's flexibility allows each instance to serve unique purposes designed for the case at hand; no two installations look alike or serve the same purpose. ${ }^{10}$ Until recently, these two tools have developed and been managed independently. However, the DSpace Foundation and Fedora Commons announced on May 12, 2009, that they would merge and form a new organization called DuraSpace. DuraSpace will continue to support and develop DSpace and Fedora and also develop new services to work with both platforms. More details about this change can be found at http://duraspace. org/pressrelease.html.

These are not the only two repository tools in use. Some libraries offer IR services using commercially developed software. The University of Utah has deployed an IR service using ContentDM, a product offered by OCLC and originally created to help organizations manage digital library collections of images and other reformatted materials. ${ }^{11}$ Digital Commons, a product of BePress, is a hosted solution for IR programs, providing libraries with an opportunity to offer programs with limited technology investment. The California Digital Library was an early adopter of Digital Commons and uses it for their eScholarship platform for all of the University of California campuses. ${ }^{12}$ Organizations with unique missions and more resources may develop comprehensive archival systems through a variety of applications and technologies, many of them specifically designed and tailored for the particular mission. The National Archives and Records Administration is now developing the Electronic Records Archive, a comprehensive electronic archives management system to handle and preserve the electronic records of the Federal Government. ${ }^{13}$ The HathiTrust, a shared repository service, is developing its own infrastructure for managing the collective digital content of more than twenty different libraries, projected to include five hundred thousand newly digitized volumes each month. ${ }^{14}$

These repository tools and implementations of them are, or should be, part of larger systems and strategies for building and caring for collections. Some models of archival and scholarly practices can help to elucidate this. The Open Archival Information Systems (OAIS) Reference Model, an ISO standard, provides a high-level conceptual overview of the organizational and technological functions necessary for the effective archival management of digital data. The OAIS model identifies four core activities in a repository system: ingest (methods to define, describe, document, and authorize the transfer of digital files); data management (the capture, storage, and analysis of metadata); archival storage (infrastructure to protect the integrity of the files at the byte level); access (provided to the user through queries, retrieval, and viewing, or to other applications or archival systems). Governing these activities are preservation planning (to develop strategies to mitigate risk and monitor technological change) and administration (such as the policy decisions that define the goals of the archive or collections and provide the support through financial and other resources). ${ }^{15}$ The OAIS framework describes not software or tools, but principles of practice that should support their use.

Another model more explicitly addresses our interactions with the data we collect and manage. The Digital Curation Centre at the University of Edinburgh has developed a Curation Lifecycle Model, which vividly captures what we do with information resources in libraries and in our colleges and universities. The lifecycle is a continuous flow of activity where information, represented in digital objects, is selected for acquisition, made accessible, discovered, used, transformed, reacquired and distributed, discovered anew, continuously appraised, and sometimes disposed of. ${ }^{16}$ This model reminds me of the "rip-mix-burn" credo associated with the Free Culture movement, which can also be crudely applied to the processes of research and scholarship: a remixing of information to create new knowledge. Our faculty and students inquire, discover, and sort information resources then analyze and synthesize them into new work, which is written, published, and distributed for the next scholars. Curation is an active process, one in which our users can and should participate. For a simple example, consider that Fedora has been designed with the assumption that digital objects have multifaceted and overlapping relationships between themselves, and that identifying and making these relationships explicit is a part of scholarship and archival work. A digital object may thus belong to many different networks of content, rather than one parent grouping, and would be accessible through all of those organizing contexts in the repository. A library might deposit a set of images as a defined collection (perhaps all coming from a single source or supplier). Users may wish to re-present those same images as constituent parts of many other collections or sets (such as "images of Italy" or "images for the Western Art Survey") and to ensure that those relationships and representations are defined, recorded, persistent, and discoverable for other users.

Libraries are moving from a business model based primarily on managing the products and the output of research and scholarship to a model based on facilitating the process of 
scholarship, teaching, and research that result in those products. No matter what technology is used, the lifecycle model for digital data curation suggests that repositories and digital data management are not distinct backroom technology operations but activities that should be functionally integrated into the mission and services of the library. Repository-enabled services will be critical to the future of scholarship in general, regardless of who offers them. Commercial agents, such as Google, can outperform existing library systems on speed and breadth of basic searches, but the preservation and scholarly use of digital assets are still fertile ground for libraries, technologists, and library users.

\section{WHAT DO WE MEAN BY SERVICES?}

For many of us, the answer to this question is obvious: Services are the activities we perform to support the researchers, students, teachers, and members of the public who use our libraries. But the term "service" also has a specific use, referring to technical functions conducted through interoperable, machine-to-machine interfaces. For instance, many digital repository collections use the Open Archives Initiative Protocol for Metadata Harvesting (OAI-PMH) to automatically share their metadata with other collections with the aim of improving discovery. Such services have little direct human intervention and provide additional functionality and data to applications, including repository systems.

Some IR programs may have developed as services looking for a need, but nothing creates a need for their services like an institutional or legal mandate to use them. Since the spring of 2008, several elite universities or their collegesincluding Harvard's Faculty of Arts and Science and John F. Kennedy School of Government, Stanford's School of Education, and all of MIT-have adopted policies requiring that all publications of their faculty also be made available in an open-access online service managed by the school. When the National Institutes of Health (NIH) began to require PubMed deposit of all publications based on NIH funding, several universities took advantage of the change to offer enhanced services to their community. For example, the University of Michigan performs NIH deposit on behalf of their own researchers, using their existing IR deposit methods as a way of gathering the articles for submission to PubMed Central. ${ }^{17}$ Other mandates will prove more complicated to meet, such as archival electronic records management. In this arena, a variety of public policy and regulatory matters have driven technology companies such as Sun, Hewlett-Packard, and EMC to develop new storage technologies that can better ensure the integrity of digital data making up the records of businesses, financial institutions, and government. Higher education institutions must meet similar requirements for auditing and disclosure, and this emerging need will challenge organizations traditionally tasked with maintaining the records and archives. The diversity of formats, record types, and relationships between these records creates a challenging environment in which to establish basic policies and practices to ensure compliance with legal requirements.

Mandates are not a reliable growth model for services. However, aggregating content is our bread-and-butter, and repository systems can enable large-scale aggregation to offer improved access. At the University of Virginia Library, the Fedora repository platform was concurrently developed with an integrated digital collections system that uses Fedora to deliver electronic texts, images, and special collections finding aids. The metaphor here would be the stacks, rather than the archive. Among the texts are books digitized by the Library alongside full-text databases published by ProQuest that are also included in their Literature OnLine (LION) product. The image collections include both purchased and licensed sets from Archivision, as well as images digitized from Virginia's Special Collections and contributed by faculty at the school. Bringing these disparate collections into an integrated collection management environment enables searches across the collections and makes it possible to create additional applications that allow users greater functionality. The Collectus tool, for example, provides a way to save sets of images and texts for use and sharing with their classes or colleagues. ${ }^{18}$

Some institutional repository services and their infrastructure serve as the basis for publication activities. Campusbased publishing has become an increasingly visible (though still very experimental) service at many research libraries and smaller ones as well. They share core assumptions with broader IR programs: Libraries, working with faculty and often with publishers such as university presses, can provide cost-effective technology to support the open distribution of research literature from within the university. Compared with IRs, these programs require an even greater degree of faculty engagement while offering a more specific service focused on distributing complete titles or collections. In her 2008 study for the Association of Research Libraries (ARL), Research Library Publishing Services, Karla Hahn reported that 44 percent of eighty responding ARL libraries offered some form of publishing service for journals, monographs, or conference proceedings. ${ }^{19}$ Open-source publishing tools such as Open Journal Systems and DPubS are frequently used for these purposes and sometimes are used to provide support for editors and authors in their review and submission processes. ${ }^{20} \mathrm{~A}$ large number of institutions reported using DSpace or Digital Commons for their publishing platform. ${ }^{21}$ Although DSpace does not offer native, out-of-the-box workflow tools for editors of publications, Digital Commons offers users editorial workflow tools designed for BePress's own journals. Given the experimental nature of these efforts, it appears that many institutions are limiting costs by first taking advantage of their existing technology investments before investigating more specialized service offerings.

Publishing, in the limited sense of distribution, can be integrated into the curriculum via repository programs as well. Like many others, Penn State-my own universitynow requires that all theses and dissertations be submitted to the Graduate School in electronic format through a system managed by the libraries. One simple model to extend this 


\section{FOR YOUR ENRICHMENT}

could include providing an electronic deposit service to undergraduate programs that require a formal thesis or paper for graduation. The Ethnography of the University Initiative (EUI) at the University of Illinois Urbana-Champaign offers another model. Through classes associated with EUI, undergraduates in different fields of study engage in original research about their campus using their familiar home environment to explore the concepts they are learning. EUI provides these students with experience publicly distributing their work by selecting research reports for inclusion in IDEALS, the University Library's repository service. The EUI collection, numbering more than 350 works, also serves as a research collection for students engaged in the program. ${ }^{22}$

Less formal, direct-to-reader publishing via media such as blogs has become an increasingly important part of daily discourse and scholarly communication. Blog software is readily available, and some institutions have created a centralized service specifically for their students and faculty. The ephemeral nature of most blogging is reflected in the software: these are first and foremost authoring and distribution tools, and do not provide the all of the capabilities for data management, preservation, and discovery that we expect to see in an archival service. The National Science Digital Library (NSDL), an initiative funded by the National Science Foundation, has launched a blog service known as Expert Voices, which features postings by multiple experts to promote online collaboration on science topics across different communities, such as K-12, researchers, and librarians. NSDL has designed Expert Voices so that it can easily interoperate with other resources in the library and so that the discussions and new content may be directly captured and managed in a repository environment based on Fedora. Rather than sitting off to the side, the data created in the blogs can easily become a part of the managed digital library. ${ }^{23}$

Even in areas of traditional, formalized publication, computationally intensive research has begun to affect the nature of the research article, its relationship to the journal as an outlet, and its relationship to the primary evidence that supports its argument. ${ }^{24}$ Figures, tables, and other graphics have provided a means to adumbrate evidence in the context of a scholarly argument in print. In the sciences, new observational tools and high performance computing resources have made possible the capture and analysis of research data on a very large scale that often extends beyond a single university or nation. Such research, and its related outputs, poses tremendous challenges for universities, libraries, and scientists to devise stable environments for secure, long-term access. At Johns Hopkins University, the Libraries have worked closely with astronomers based at Hopkins and with the National Virtual Observatory to explore what technological capacity and organizational expertise will be required to capture and manage astronomical data. An element of this project has included work with major publishers in the field to define and test persistent methods of publishing experimental data sets along with the formal written article reporting on the research. Here the library has begun to develop a service that supports not only their local community but potentially the entire profession of astronomy. ${ }^{25}$

\section{CONCLUSIONS}

After all the hype, today it is most critical to identify the content-driven services that can be offered through "repositories," and which of these our libraries need to offer to our clients, however we define them. I am of two minds about whether all libraries should offer such services. On the one hand, we do have a mission to collect, manage, preserve, and provide access to resources for our user base and the wider world. But we are well past the days when all collections needed to reside physically on each campus, and we are approaching times when replication of similar technology services on each campus may prove to be economically impossible. If content management and delivery services have a limited audience on a given campus, it may be better to partner with others to offer or to rent the needed technology. That is heresy to many because it contradicts our philosophy of retaining control over "our" materials. But scale matters, and if we cannot achieve it on our own, we will risk poorly managing services that have limited use.

No library should implement a digital repository program without examining the role it will play in its broader strategy for collection development, stewardship, and providing access to its primary constituencies. That strategy should be based on a clear understanding of the community's needs and the requirements for long-term stewardship of the data collected. Most importantly, it should include a critical assessment of the library's ability to fully meet those needs, including funding, the skills of its staff, and the benefit of the service relative to the cost of operating it. ${ }^{26}$ We cannot do everything, especially now, and we should be willing to walk away from that which doesn't work for us. As an administrator, I appreciate that this is much more easily said than done.

We tend to build silos for our collections and services, either because of organizational politics, convenience, feasibility, or just because we are predisposed to think about fitting things into buckets. Some libraries that are offering significant services for original publications-such as journals, for articles such as pre- or postprints, and for large collections of reformatted or born-digital materials-operate some or all of these services through different software and different operational divisions of that library. Heterogeneous content and heterogeneous communities require heterogeneous services, but a coherent organizational strategy and economies of scale should underlie these.

Access services to repository content present their own challenges. The relative quality of the user interfaces and overall user experience of interacting with our tools and systems continues to be a problem throughout all library systems. California Digital Library has begun an effort to revamp user interfaces and functionalities in their eScholarship repository-which is unusual given their use of a commercial service provider, BePress-but this takes many resources to 
do effectively. I once solicited feedback from a faculty member using a cross-collection metadata search for a digital library collection. Comparing it to "those finding aids they make me use in special collections," he said it looked like librarians created it for librarians. Ouch.

Then there is the issue of authenticity and value, and what that means in different contexts and for different communities. While software can help to ensure that the digital file's integrity remains stable, it is still difficult to identify and explain variations in the multiple versions of materials deposited in different repositories (Google Scholar can at least identify related versions, however). Some repository services don't easily support versioning, and we might be reluctant to withdraw items deposited, even if an author offered a substantial revision in its place. But if we deliver a draft of an article in our repository, but perhaps don't subscribe to the outlet producing the finished product, how do we help our users know how to evaluate what they find in our collections? Here public services, collection development policies, and technology programs need to work in concert to help convey the context for what is found online in our electronic collections.

When we talk about repositories, or better, the services we offer through them, we should be discussing the social side of technology and its adoption. Repository programs are still exotic, or even scary, to too many of our colleagues, and most librarians were never trained to make the sale for experimental services or projects. But those programs must be integrated into the rest of the library's services. Public services librarians meet students every day in the classroom, in the library, or online, and, despite their slight reluctance to pay us a visit in the library, faculty still call upon us. All of us have a responsibility to gently query our teaching and research colleagues to divine the needs that they didn't know they had, and try to match those to the services we can provide. That, in turn, requires more active communication across the divisions of our libraries to ensure that the programs we offer are integrated into instruction, reference, and collection development. In some fields, perhaps especially in the sciences, many researchers cannot imagine why or how the library could do anything but subscribe to journals, even as they struggle to document and organize their work. We have huge obstacles to overcome, but the library remains a trusted brand and our partners are out there and talking. Johanna Drucker, a professor of information studies at the University of California at Los Angeles, wrote recently in the Chronicle of Higher Education that

the design of new [online] environments for performing scholarly work cannot be left to the technical staff and to library professionals. The library is a crucial partner in planning and envisioning the future of preserving, using, even creating scholarly resources. So are the technology professionals. But in an analogy with building construction, they are the architects and the contractors. The creation of archives, analytic tools, and statistical analyses of aggregate data in the humanities (and in some other scholarly fields) requires the combined expertise of technical, professional, and scholarly personnel. ${ }^{27}$

In other words, we have to engage and guide researchers, but we also must let them lead us, possibly where we might not have expected, or maybe even wouldn't want them to go. We can't assume we know best, or the library will end up running a repository, i.e., "a place in which a dead body is deposited; a vault or sepulchre."

\section{References and Notes}

1. OED Online, s.v. "Repository" www.oed.com (accessed May 7, 2009).

2. Jeffrey R. Young, "'Superarchives' Could Hold All Scholarly Output: Online Collections by Institutions May Challenge the Role of Journal Publishers," Chronicle of Higher Education 48, no. 43 (July 5, 2002): A29-A30.

3. Raym Crow, The Case for Institutional Repositories: A SPARC Position Paper (Washington, D.C.: The Scholarly Publishing \& Academic Resources Coalition, 2002): 4

4. Andrea L. Foster, "Papers Wanted: Online Archives Run by Universities Struggle to Attract Material," Chronicle of Higher Education 50, no. 42 (June 25, 2004): A37.

5. Dorothea Salo, "Unappetizing Metaphors," online posting, Mar. 6, 2006, Caveat Lector, http://cavlec.yarinareth.net/2006/03/06/ unappetizing-metaphors (accessed May 7, 2009).

6. Clifford A. Lynch and Joan K. Lippincott, "Institutional Repository Deployment in the United States as of Early 2005," D-Lib Magazine 11, no. 9 (Sept. 2005), www.dlib.org/dlib/september05/ lynch/09lynch.html (accessed May 7, 2009).

7. Throughout this essay, I use the term data broadly to refer to just about anything that is in digital form and of enduring interest to scholars or librarians.

8. Catherine Mitchell, "Let's Stop Talking About Repositories: A Study in Perceived Use-Value, Communication and Publishing Services," (presentation at the SPARC Digital Repositories Meeting 2008, Baltimore, Maryland, November 18, 2008).

9. MIT Libraries, DSpace (Apr. 28, 2001), http://web.archive.org/ web/20010502090307/www.dspace.org/home.html, accessed through the Internet Archive Wayback Machine, www.archive .org/web/web.php (accessed June 19, 2009).

10. Fedora Commons, www.fedora-commons.org (accessed May 7 , 2009).

11. See http://uspace.utah.edu and www.contentdm.com (accessed May 7, 2009).

12. The Berkeley Electronic Press, www.bepress.com/ir (accessed May 7, 2009).

13. Though it considered contracting with the Harris Corporation to build a system based on Fedora, it ultimately awarded a contract to Lockheed Martin, which is designing the system on that basis of a variety of internally developed methods and applications. See www.archives.gov/era (accessed July 29, 2009).

14. HathiTrust: A Shared Digital Repository, www.hathitrust.org (accessed May 7, 2009).

15. The HathiTrust explicitly references this model when describing the architecture it is designing. Consultative Committee for Space Data Systems, Reference Model for an Open Archival Information System (OAIS) (Washington, D.C.: National Aeronautics and Space Administration, 2002), http://public.ccsds.org/publications/

CONTINUED ON PAGE 32 


\section{INFORMATION LITERACY AND INSTRUCTION}

41. Ibid., 162-63.

42. Jennifer Lann, "Landmark College Library," in Improving the Quality of Library Services for Students with Disabilities, ed. Peter Hernon and Philip J. Calvert (Westport, Conn: Libraries Unlimited, 2006): 72-80.

43. Ibid., 77-78; see table 1 for definitions of UDI principles.

44. Heidi Neumann, "What Teacher-Librarians Should Know about Universal Design," Teacher Librarian 31, no. 2 (Dec. 2003): $17-20$.

45. Alexander Gyamfi, "Tailoring Instruction for Students with Disabilities," in Information Literacy That Works: A Guide to Teaching by Discipline and Student Population, ed. Patrick Ragains (New York: Neal-Schuman, 2006): 71-93.

46. Debbie Creamer, "Universal Instructional Design for Libraries," Colorado Libraries 33, no.4 (2007): 13.

47. Ibid., 14.

48. Ibid., 14-15.

49. Joan M. McGuire and Sally S. Scott, "An Approach to Inclusive College Teaching: Universal Design for Instruction," Learning Disabilities: A Multidisciplinary Journal 14, no. 1 (2006): 23.

50. Ibid., 26

51. Rose et al., "Universal Design for Learning in Postsecondary Education: Reflections on Principles and the Application," 137.

52. Zentall, "Theory and Evidence Based Strategies for Children with Attentional Problems," 831.

53. CAST, Universal Design for Learning Guidelines Version 1.0, 13.

54. McGuire and Scott, "An Approach to Inclusive College Teaching," 23.
55. Zentall, "Theory and Evidence Based Strategies for Children with Attentional Problems," 826.

56. McGuire and Scott, "An Approach to Inclusive College Teaching: Universal Design for Instruction," 23.

57. Ibid

58. Ibid, 24.

59. Zentall, "Theory and Evidence Based Strategies for Children with Attentional Problems," 826.

60. McGuire and Scott, "An Approach to Inclusive College Teaching," 24.

61. Mel Silberman, "Ten Layouts for Setting up a Classroom," in Active Learning: 101 Stategies to Teach Any Subject (Needham Heights: Allyn \& Bacon, 1996): 9-16.

62. McGuire and Scott, "An Approach to Inclusive College Teaching," 24.

63. Nancy Fried Foster, Nancy Fried, and Susan Gibbons, Studying Students: The Undergraduate Research Project at the University of Rochester (Chicago: Association of College and Research Libraries, 2007): 67

64. Lann, "Landmark College Library," 78.

65. Association of College and Research Libraries, "Standards for Proficiencies for Instruction Librarians and Coordinators," www .ala.org/ala/mgrps/divs/acrl/standards/profstandards.cfm (accessed June 22, 2009), proficiencies 3.1, 6.6, 6.7, 9.2, and 12.2.

66. MacLean Gander and Solvegi Shmulsky, "Universal Design for Instruction: Current Theory and Practice" (working paper, Theoretical Framework Project, Landmark College, Putney, Vt., 2008), 2.
FOR YOUR ENRICHMENT CONTINUED FROM PAGE 23

archive/650x0bl.pdf (accessed June 19, 2009).

16. Sarah Higgins, "The DCC Curation Lifecycle Model," The International Journal of Digital Curation 3, no. 1 (2008), www.ijdc.net/ index.php/ijdc/article/viewFile/69/48 (accessed May 7, 2009). The diagram may also be found at www.dcc.ac.uk/docs/publications/ DCCLifecycle.pdf.

17. See the University of Michigan Research Office's documentation on Compliance with NIH Access Policy, www.drda.umich.edu/ policies/federal/nihpub.html (accessed July 26, 2009)

18. See www.lib.virginia.edu/digital/collections (accessed July 26, 2009).

19. Karla Hahn, Research Library Publishing Services: New Options for University Publishing (Washington, D.C.: Association of Research Libraries, 2008), www.arl.org/bm doc/research-library-publish ing-services.pdf (accessed May 7, 2009).

20. See Public Kowledge Project: Open Journal Systems, http://pkp .sfu.ca/?q=ojs and DPubs: Digital Publishing System, http://dpubs .org (accessed July 29, 2009).

21. Hahn, Research Library Publishing Services.

22. See Illinois Digital Environment for Access to Learning and Scholarship, Ethnography of the University Initiative, www.ideals.uiuc .edu/handle/2142/755 (accessed July 26, 2009)

23. See Expert Voices, Recent Posts, http://expertvoices.nsdl.org (accessed July 26, 2009).

24. Clifford Lynch, "The Shape of the Scientific Article in the Developing Cyberinfrastructure," CTWatch Quarterly 3, no. 3 (Aug. 2007), www.ctwatch.org/quarterly/articles/2007/08/the-shape-of-the -scientific-article-in-the-developing-cyberinfrastructure (accessed May 7, 2009).

25. Sayeed Choudhury et al., "Digital Data Preservation for Scholarly Publications in Astronomy," The International Journal of Digital Curation 2, no. 2 (2007), www.ijdc.net/index.php/ijdc/article/ viewFile/41/26 (accessed May 7, 2009).

26. Dorothea Salo has quite effectively written about the failure of institutional repository programs, attributing much of it to a failure of vision and leadership that results in a poor alignment of resources with the program goals. See Dorothea Salo, "Innkeeper at the Roach Motel," Library Trends 57, no. 2 (2008): 98-123.

27. Johanna Drucker, "Blind spots: Humanists Must Plan Their Digital Future," Chronicle of Higher Education 55, no. 30 (Apr. 13, 2009): B6. 